\title{
Significance of ST-segment Depression during Paroxysmal Supraventricular Tachycardia
}

\author{
Shahana Zaman ${ }^{1}$, Lima Asrin Sayami ${ }^{1}$, Muhammad Abdur Rahim², AKM Monwarul Islam¹, \\ Mohammad Ullah ${ }^{1}$, Shaila Nabi ${ }^{1}$, M Atahar Ali $^{1}$ \\ ${ }^{1}$ Department of Cardiology, National Institute of Cardiovascular Diseases, Dhaka, ${ }^{2}$ Department of \\ Nephrology, BIRDEM, Dhaka
}

Key words:
ST-segment
depression,
supraventricular
tachycardia,
AVRT, AVNRT,
Coronary artery
disease.

\begin{abstract}
:
Background: ST-segment depression in ECG is a common finding during paroxysmal supraventricular tachycardia. The exact mechanism and etiology of this ST-segment depression is not always evident. In this study we have tried to evaluate the significance of ST-segment depression during supraventricular tachycardia.
\end{abstract}

Methods: Hospitalized patients for elective electrophysiological study with previous (EPS) history of supraventricular tachycardia with or without ST-segment depression were evaluated clinically, by coronary angiogram and EPS. Data were analyzed by appropriate statistical methods and comparison made between groups with ST-segment depression (Group A) and without ST-segment depression (Group B).

Results: Total number of patients was 66. Equal number of patients (33) was in each group. The mean age of patients was 43.8 years. There was female predominance (M:F ratio 2:3). The mean heart rate during supraventricular tachycardia was 161 beats/min. Age, sex, coronary artery disease risk factors and heart rate during an episode of supraventricular tachycardia did not have any significant influence on ST-segment depression. Significant coronary artery disease was found in two patients in Group A and one patient in Group B. Electrophysiological study revealed that Atrio ventricular reentry tachycardia (AVRT) and AV nodal reentry tachycardia (AVNRT) were present in 28 (42.4\%) and $38(57.6 \%)$ cases respectively. Patients of group A exhibit AVRT significantly more than patients of group B.The sensitivity of ST-segment depression in correctly diagnosing coronary artery disease (CAD) was $66.7 \%$ while the specificity was $50.8 \%$. The sensitivity of ST-segment depression in correctly differentiating AVRT was $83.3 \%$ while the specificity was $66.7 \%$. The positive predictive value (PPV) and Negative predictive value (NPV) of the test were $75 \%$ and $76.9 \%$ respectively.

Conclusion: ST-segment depression during episode of supraventricular tachycardia is a poor indicator of coronary artery disease. Presence of ST-segment depression can differentiate AVRT from AVNRT. However, $\geq 2 \mathrm{~mm} S T$-segment depression was proved to be an excellent predictor of $A V R T$.

(Cardiovasc.j. 2015; 7(2): 93-97)

\section{Introduction:}

Paroxysmal supraventricular tachycardia (PSVT) is one of the most common abnormal cardiac rhythms seen in the emergency department. ${ }^{1}$ It is defined as a tachycardia with a QRS less than 0.12 sec duration where conduction begins proximal to the bundle of His. ${ }^{2}$ One group of supraventricural tachycardia (SVT) is independent of the atrioventricular (AV) node which includes sinus tachycardia and the atrial tachycardias. The other AV node dependent group includes AV node re- entry tachycardia (AVRT), AV re-entrant tachycardia (AVNRT) and junctional tachycardias. The AVRT may be associated with an accessory pathway. The AVNRT, in which the re-entrant circuit is confined to the AV node or the region around the AV node, is the most common type of PSVT in adults. ${ }^{3}$

ST-segment depression during PSVT is observed frequently, but the mechanism of this electrocardiographic repolarization changes is not well understood. The role of coronary artery

Address of Correspondence : Dr. Shahana Zaman, Department of Cardiology, National Institute of Cardiovascular Diseases, Dhaka, Bangladesh, e-mail: bance2003@yahoo.com 
disease $(\mathrm{CAD})$ and myocardial ischemia and a rate related electrocardiographic injury in the genesis of ST-segment depression during PSVT have been investigated in different studies. ${ }^{4-8}$ However, STsegment depression occurring during SVT in elderly patients or associated with symptoms of ischemia mandate the exclusion of coexisting coronary artery disease. It is also found that STsegment depression during SVT is more pronounced during AVRT than AVNRT. ${ }^{9}$

In this study, we have evaluated the significance of ST-segment depression during PSVT in our setting.

\section{Methodology}

This cross-sectional observational study was conducted in the National Institute of Cardiovascular Diseases (NICVD), Dhaka, Bangladesh from August 2010 to March 2011with the aims to determine the significance of STsegment depression during PSVT, to find out the association between ST-segment depression during PSVT and CAD and to determine the value of magnitude of ST-segment depression during PSVT to differentiate between AVRT and AVNRT. Patients with documented PSVT admitted into the NICVD for elective electrophysiological study (EPS) constituted the study population. Patients with known ischaemic heart disease, persistent or intermittent bundle branch block, left or right ventricular hypertrophy, organic valvular disease, congenital heart disease, electrolyte abnormalities, digitalis or psychotrophic drug treatment and features of pre-excitation were excluded from the study. Patients were divided into two groups based on presence or absence of ST-segment depression during an episode of SVT. The extent of STsegment depression was measured in each lead at the point of the greatest ST-segment displacement within an $80 \mathrm{msec}$ interval of the $\mathrm{J}$ point and expressed in millimeters $(10 \mathrm{~mm}=$ $1 \mathrm{mV}$ ). Measurement was done by calipers. Group A - patients with PSVT with ST-segment depression. Depending on the magnitude of STsegment depression this group was subdivided into Group A1, ST-depression $\geq 2 \mathrm{~mm}$ and GroupA2, ST-depression $<2 \mathrm{~mm}$. Group B - patients with PSVT without ST-segment depression. All patients underwent both coronary angiogram (CAG) and EPS.

\section{Results:}

Total number of patients was 66. Group A had 33 patients and Group B had 33 patients. The mean $( \pm \mathrm{SD})$ age was $43.8 \pm 1.2(22-63)$ years. Male to female ratio was roughly $2: 3$. Presenting complaints included palpitation $(61,92.4 \%)$, dyspnoea $(40,60.6 \%)$, chest pain $(23,34.8 \%)$, dizziness $(8,12.1 \%)$ and syncope $(7,10.6 \%)$. The mean heart rate during SVT was $161 \pm 16$ beats/ min. On resting ECG findings, $4.5 \%$ patients exhibited atrial ectopics and $6.1 \%$ ventricular ectopics. Age, sex, CAD risk factors and heart rate during an episode of SVT did not have any significant influence on ST-segment depression (Table I).

Significant CAD was found in two patients in Group A and one patient in Group B. No significant difference was observed between two groups regarding CAD (Table II).Electrophysiological study revealed that AVRT and AVNRT were present in $28(42.4 \%)$ and $38(57.6 \%)$ cases respectively. Patients of group A exhibit AVRT significantly more than patients of group B (Table II).

Table III shows the accuracy of ST-segment depression as a screening test in diagnosing CAD. The sensitivity of ST-segment depression in correctly diagnosing $\mathrm{CAD}$ of those who have the disease was $66.7 \%$ while the specificity of the test was $50.8 \%$. The positive predictive value (PPV) of the test was $6.1 \%$ and the negative predictive value (NPV) was $97 \%$. The percentages of false positive and false negative yielded by the test were $93.9 \%$ and $3.3 \%$ respectively.

The accuracy of magnitude of ST-segment depression as a screening test in differentiating AVRT from AVNRT was shown in table IV. The sensitivity of ST-segment depression in correctly differentiating AVRT of those who have the condition was $83.3 \%$ while the specificity of the test in diagnosing AVRT was $66.7 \%$. The PPV and NPV of the test were $75 \%$ and $76.9 \%$ respectively. The percentage of false positives and false negatives yielded by the test were $25 \%$ and $23.1 \%$ respectively. 
Table-I

Base-line characteristics of both groups

\begin{tabular}{|c|c|c|c|}
\hline Base-line characteristics & Group A (n=33) & Group B $(\mathrm{n}=33)$ & p-value \\
\hline \multicolumn{4}{|l|}{$\overline{\text { Age }(\text { years) }})^{\#}$} \\
\hline$\leq 30$ & $2(6.1)$ & $3(9.1)$ & \multirow{4}{*}{0.720} \\
\hline $31-40$ & $14(42.4)$ & 10(30.3) & \\
\hline $41-50$ & $8(24.2)$ & 11(33.3) & \\
\hline$>50$ & $9(27.3)$ & $9(27.3)$ & \\
\hline \multicolumn{4}{|l|}{$\operatorname{Sex}^{\#}$} \\
\hline Male & $15(45.5)$ & $12(36.4)$ & \multirow[t]{2}{*}{0.453} \\
\hline Female & $18(54.5)$ & $21(63.6)$ & \\
\hline \multicolumn{4}{|l|}{ Presence of risk factors } \\
\hline Smoking $\#$ & $6(18.2)$ & $7(21.2)$ & 0.757 \\
\hline Hypertension* & $5(15.2)$ & $3(9.1)$ & 0.354 \\
\hline Diabetes* & $5(15.2)$ & $2(6.1)$ & 0.213 \\
\hline Dyslipidaemia* & $2(6.1)$ & $1(3.3)$ & 0.635 \\
\hline Family history of CAD* & $1(3.3)$ & $1(3.3)$ & 0.754 \\
\hline \multicolumn{4}{|c|}{ Heart rate during SVT (beats/m) } \\
\hline $121-140$ & $2(6.1)$ & $3(9.1)$ & \multirow{4}{*}{0.665} \\
\hline $141-160$ & 11(33.3) & $15(45.5)$ & \\
\hline $161-180$ & $14(42.4)$ & $11(33.3)$ & \\
\hline$>180$ & $6(18.2)$ & $7(21.2)$ & \\
\hline
\end{tabular}

Figures in the parentheses denote corresponding percentage.

\# Data were analysed using Chi-square Test.

* Fisher's Exact Test was employed to analyse the data

Table-II

Association of CAD and types of SVT with ST segment depression

\begin{tabular}{lccc}
\hline & $\begin{array}{c}\text { ST-segment } \\
\text { depression present } \\
\text { Group A (n=33) }\end{array}$ & $\begin{array}{c}\text { ST-segment } \\
\text { depression absent } \\
\text { Group B (n=33) }\end{array}$ & p-value \\
\hline CAG* & $31(93.9)$ & $32(96.7)$ & 0.05 \\
Normal & $2(6.1)$ & $1(3.3)$ & \\
CAD & $18(54.5)$ & $10(30.3)$ & 0.046 \\
Type of SVT (EPS)\# & $15(45.5)$ & $23(69.7)$ & \\
AVRT & AVNRT &
\end{tabular}

Figures in the parentheses denote corresponding percentage.

* Fisher's Exact Test was employed to analyze the data

\# Data were analyzed using Chi-square Test.

Table-III

Accuracy of ST segment depression in diagnosing ischemia

\begin{tabular}{lccc}
\hline ST-segment depression & $\begin{array}{c}\text { CAG findings: } \\
\text { CAD present }\end{array}$ & $\begin{array}{c}\text { CAG findings: } \\
\text { CAD absent }\end{array}$ & Total \\
\hline Present & 2 & 31 & 33 \\
Absent & 1 & 32 & 33 \\
\hline Total & 3 & 63 & 66 \\
\hline
\end{tabular}


Table-IV

Accuracy of magnitude ST segment depression in diagnosing AVRT

\begin{tabular}{lccc}
\hline ST-segment depression & Type of SVT: AVRT & Type of SVT: AVNRT & Total \\
\hline$\geq 2 \mathrm{~mm}$ & 15 & 5 & 20 \\
$<2 \mathrm{~mm}$ & 3 & 10 & 13 \\
\hline Total & 18 & 15 & 33 \\
\hline
\end{tabular}

\section{Discussion:}

The mean age of our study population was 43.8 years which was much lower than two other studies. ${ }^{10,11}$ In the present study female predominance was observed in both groups. Higher percentage of female patients were shown in both groups by Bukkapatnamet al. ${ }^{10}$ and Gulecetet al. ${ }^{11}$

Palpitation was the commonest complaint in this study. Other presenting features were dyspnoea, chest pain, dizziness and syncope. Clinical presentation were similar in two other studies. ${ }^{12,13}$ Among the $\mathrm{CAD}$ risk factors, incidence of smoking was highest in both groups followed by hypertension. Bukkapatnam et al. on the contrary, found hypertension as the most prevalent risk factors in both groups. ${ }^{10}$

Mean heart rate in current study was higher in

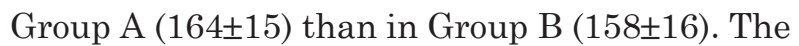
relation between heart rate and ST-segment depression during PSVT was somewhat controversial. Takayanagi et al. reported a close correlation between ST-segment score (sum of the ST-segment depression in 12 leads during PSVT) and PSVT rate. ${ }^{14} \mathrm{Kim}$ et al. also concluded that ST depression during PSVT was a rate-related phenomenon. ${ }^{8}$ Both Bukkapatnam et al. and Gulec et al. showed increased mean heart rate in ST-segment depression group in comparison to the group without ST-segment depression. ${ }^{10,11}$ However, Imrie et al. could not und a positive correlation between heart rate and ST-segment depression during SVT. ${ }^{15}$ In this study, we also could not find a significant relation between STsegment depression and PSVT rate. A possible explanation of higher heart rate in ST-segment depression group was due to an increased metabolic demand because of suddenly increased cardiac work.

Coronary artery disease was found in 2 patients in group A and 1 patient in Group B. They were relatively older and had other risk factors for coronary artery disease. However, no significant relation was observed between coronary artery disease and ST-segment depression. Both Bukkapatnam et al. and Gulec et al. found similar results. ${ }^{10,11}$ It had been suggested that ST-segment depression during PSVT could be the result of release of catecholamines and augmented sympathetic tone, as catecholamines can alter phase 2 of the action potential. ${ }^{16}$

In the present study, AVRT was significantly more common in Group A than Group B. Fassini et al. showed ST-segment depression $\geq 2 \mathrm{~mm}$ was present more often in AVRT than AVNRT. ${ }^{17}$ Imrie JR et al. observed that ST-segment depression during PSVT was mostly due to AVRT. ${ }^{15}$ STsegment depression was more pronounced in patients with AVRT compared to AVNRT, due to combination of a longer VA interval and total atrial activation time in AVRT patients. ${ }^{18}$

This study demonstrated the accuracy of STsegment depression as a screening tool in diagnosing CAD. Sensitivity of ST-segment depression was $66.7 \%$ while the specificity of the test was $50.8 \%$. The positive predictive value (PPV) of the test was $6.1 \%$ and the negative predictive value (NPV) of the test was $97 \%$. The percentages of false positive and false negative yielded by the test were $93.9 \%$ and $3 \%$ respectively. Jiang et al, Nelson et al, Imrie et al, Pestas et al. and Gulec et al concluded that ST-segment changes observed during narrow QRS complex tachycardia were common, nonspecific and a poor predictor of underlying coronary artery disease. ${ }^{19,5,15,4,11}$

This study also described that the accuracy of magnitude of ST-segment depression as a screening test for differentiating AVRT from AVNRT. For AVRT, the sensitivity of ST-segment depression was $83.3 \%$ while the specificity was $66.7 \%$. The PPV and NPV of the test were $75 \%$ and $76.9 \%$ respectively. Letsas et al. found that the overall sensitivity, specificity, PPV and NPV 
of ST-segment depression for discriminating AVRT from AVNRT were $97.22 \%, 58.11 \%, 53.03 \%, 97.73 \%$ respectively. ${ }^{20}$

\section{Study limitation:}

The current study had got some limitations. The sample size was small.Coronary angiogram was analyzed by visual estimation in standard views. Bio-marker of coronary artery disease like troponin I was not done in this study.

\section{Conclusion:}

From the current study, it can be concluded that ST-segment depression during episode of PSVT is a poor indicator of CAD with specificity only $50 \%$. Presence of ST-segment depression can differentiate AVRT from AVNRT, further $\geq 2 \mathrm{~mm}$ ST-segment depression was proved to be an excellent predictor of AVRT with positive predictive value of $75 \%$.

\section{Conflict of Interest - None.}

\section{References:}

1. Orejarena L, Vidaillet H, DeStefano F, Nordstrom D, Vierkant R, Smith P, et al. Paroxysmal supraventricular tachycardia in the general population. J Am Coll Cardiol 1998;31:150-157.

2. Gilbert C. Common supraventricular tachycardias: mechanisms and management. AACN Clin Issues 2001; 12:100-113.

3. Kadish A, Passman R. Mechanisms and management of paroxysmal supraventricular tachycardia. Cardiol Rev 1999;7:254-264.

4. Petsas AA, Anastassiades LC, Antonopoulos AG. Exercise testing for assessmentof the significance of ST depression observed during episodes of paroxysmal supraventricular tachycardia. Eur Heart J 1990; 11:974 -979.

5. Nelson SD, Kou WH, Annesley T, De Buitleir M, Morady F. Significance of ST segment depression during paroxysmal supraventricular tachycardia. J Am Coll Cardiol 1988; 12:383-387.

6. CastellanosA,InteriorJrA,MyerburgRJ. The resting Electrocardiogram. In: Fuster V, Alexander RW, O'Rourke RA eds. Hurst's The Heart, $12^{\text {th }}$ edn. New York: McGraw-Hill, 2008:303.

7. Calkins H. Supraventricular Tachycardia,AV Nodal Reentry and Wolf -Parkinson-White Syndrome. In: Fuster V, Alexander RW, O'Rourke RA eds. Hurst's The Heart, $12^{\text {th }}$ edn. New York: McGraw-Hill,2008,P985,994 .

8. Kim YN, Sousa J, EL- Attasi R, Calkins H, Langberg JJ, Morady L. Magnitude of ST segment depression during paroxysmal supraventricular tachycardia.Am Heart J 1991:122:1486-1487.

9. Jaeggi ET, Gilljam T, Bauersfeld U, Chiu C, Gow R. Electrocardiographic differentiation of typical Atrioventricular node reentrant tachycardia from atrioventricular reciprocating tachycardia mediated by concealed accessory pathway in children. Am J Cardiol 2003, 91:1084-1089.

10. Bukkapatnam RN, Robinson M, Samuel T, Daniel E, Amsterdam E, SrivatsaUN. Relationship ....Myocardial Ischemia and Injury to Coronary Artery Disease in Patients With Supraventricular Tachycardia . J Am Coll Cardiol 2010; 106:374-377.

11. Gulec S, Ertas F, Karaoouz R, et al. Value of ST-segment depression during paroxysmal supraventricular tachycardia in the diagnosis of coronary artery disease. Am J Cardiol 1999;83:458-460.

12. Hashem S. Radiofrequency catheter ablation of left free wall accessory pathways: Comparison between retrograde and transeptal approach. FCPS cardiology thesis. Bangladesh, BCPS. 2010.

13. Hossain M. Efficacy and safety of radiofrequency catheter ablation of supraventricular tachycardia. FCPS Cardiology thesis. Bangladesh, BCPS. 2007.

14. Takayanagi K, Hoshi H, Shimizu M, et al. PronouncedST-segment depression during paroxysmal supraventricular tachycardia. Jpn Heart J 1993; 34:269278.

15. Imrie JR, Yee R, Klein GJ, et al. Incidence and clinical significance of ST segment depression in supraventricular tachycardia. Can $J$ Cardiol 1990;6:323-326.

16. Cannon RO III, Schenke WH, Quyyumi A, et al. Comparison of exercise testing with studies of coronary flow reserve in patients with microvascular angina. Circulation 1991; 83:77-81.

17. Fassini G, Riva S, Della Bella P, Carbucicchio C, Tondo C. Analysis of changes in repolarization for the differential diagnosis of narrow QRS supraventricular tachycardia and the site of the accessory pathway. Cardiologia 1996 Sep;41(9):805-806.

18. Riva SI, Della Bella P, Fassini G, et al. Value of analysis of ST segment changes during tachycardia in determining type of narrow QRS complex tachycardia. J Am Coll Cardiol1996;27:1480-1485.

19. Lin YJ, Tai CT, Chiang CE, et al. Mechanism of repolarization change during initiation of supraventricular tachycardia. J Cardiovasc Electrophysiol 2004;15:1233-1237.

20. Letsas KP, Weber R, Siklody CH, Mihas CC, Stockinger J, Blum T, et al. Electrocardiographic differentiation of common type atrioventricular nodal reentrant tachycardia from atrioventricular reciprocating tachycardia via a concealed accessory pathway. Acta Cardiol 2010 Apr;65(2):171-176. 